\title{
Diagnostic Accuracy of Trichoscopy in Inflammatory Scalp Diseases: A Systematic Review
}

\author{
Joanna Golińska Marta Sar-Pomian Lidia Rudnicka \\ Department of Dermatology, Medical University of Warsaw, Warsaw, Poland
}

\section{Keywords}

Dermoscopy · Eczematous skin diseases · Psoriasis · Scalp dermatoses · Trichoscopy

\begin{abstract}
Background: The common inflammatory scalp diseases, such as psoriasis, seborrheic dermatitis, lichen planopilaris, discoid lupus erythematosus, contact dermatitis, or pemphigus may share similar clinical features. Objective: To identify and systematically review the available evidence on the accuracy of trichoscopy in inflammatory scalp disorders. Methods: A systematic review was performed according to Preferred Reporting Items for Systematic Reviews and MetaAnalyses (PRISMA) guidelines. A total of 58 articles were included in the analysis. Results: The following trichoscopy features were found to show the highest specificity for the respective diseases: in psoriasis: diffuse scaling, simple and twisted red loops, red dots and globules, and glomerular vessels; in seborrheic dermatitis: atypical vessels, thin arborizing vessels, and structureless red areas; in discoid lupus erythematosus: follicular plugs and erythema encircling follicles; in lichen planopilaris: milky red areas or fibrotic patches; in contact dermatitis: twisted red loops; in pemphigus foliaceus: white polygonal structures and serpentine vessels; in pemphigus vulgaris: red dots with whitish halo and lace-
\end{abstract}

karger@karger.com

(C) 2021 S. Karger AG, Basel

www.karger.com/drm

Karger! like vessels; and in dermatomyositis: lake-like vascular structures. Limitations: Different nomenclature and variability in parameters, which were analyzed in different studies. Conclusion: This systemic analysis indicates that trichoscopy may be used with high accuracy in the differential diagnosis of inflammatory scalp diseases.

(c) 2021 S. Karger AG, Basel

\section{Introduction}

The differential diagnosis of erythematous and desquamative scalp lesions may be challenging. Diseases such as psoriasis, seborrheic dermatitis, contact dermatitis, lichen planopilaris, tinea capitis, discoid lupus erythematosus, pemphigus foliaceus, pemphigus vulgaris, dermatomyositis, or syphilis present with similar clinical manifestations, most commonly as erythematous patches and scaling, often associated with pruritus [1-6].

Trichoscopy is a diagnostic method $[7,8]$ widely used for the differential diagnosis of hair loss. Recently, several research articles addressed the possible application of trichoscopy in inflammatory scalp diseases.

The aim of this systematic review was to evaluate the diagnostic value of trichoscopy in inflammatory diseases of the scalp. 
Fig. 1. Preferred Reporting Items for Systematic Reviews and Meta-Analyses (PRISMA) flow diagram.

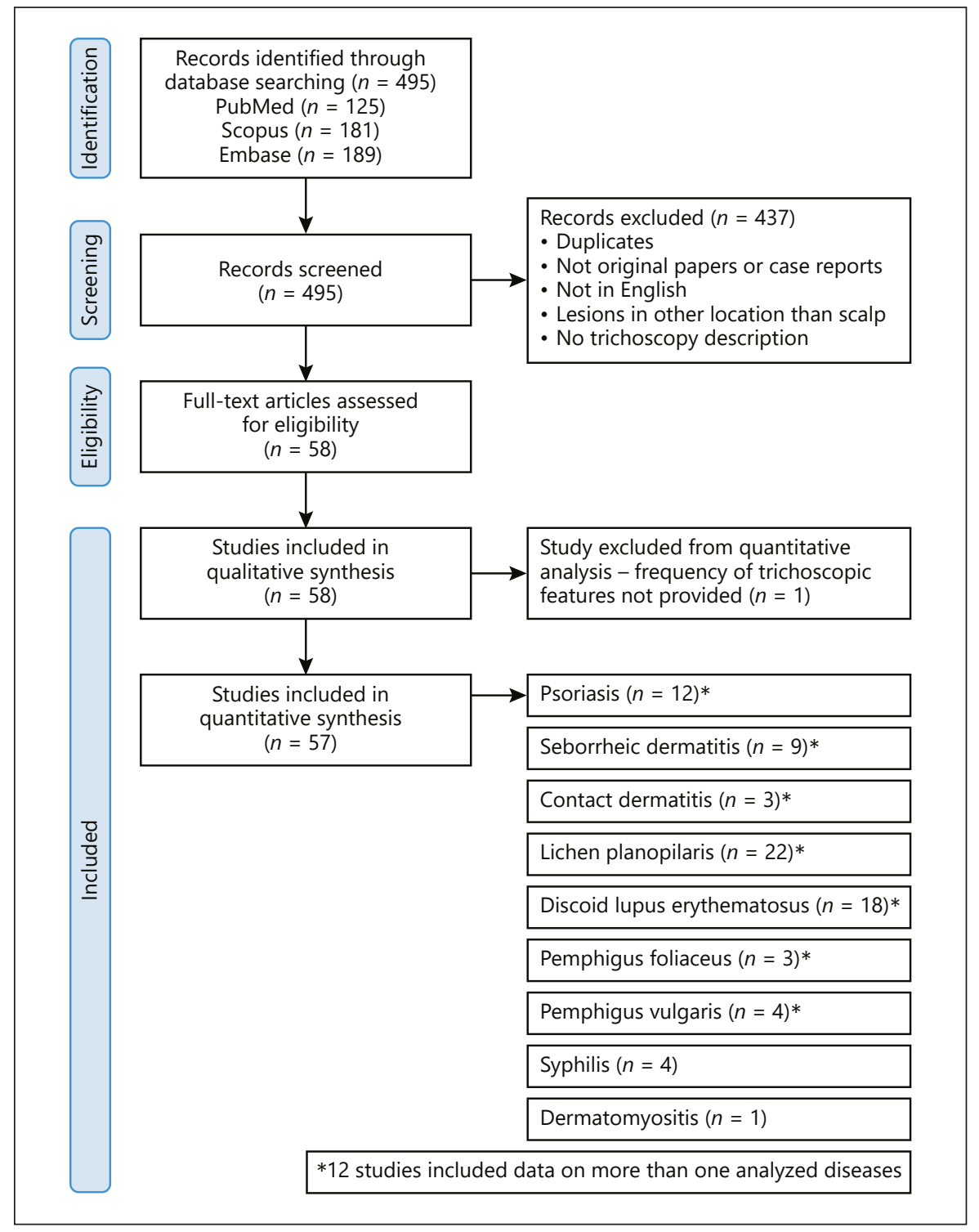

\section{Methods}

A systematic search of three databases - PubMed, Scopus, and Embase - was performed in February 2021 (Fig. 1). A total of 58 articles (31 original studies and 27 case reports) were included into the review and analysis. Articles concerning data exclusively on tinea capitis were excluded as a comprehensive review of literature on this topic has been recently published [9]. The frequency of trichoscopic features was reported in reference to the total number of included patients with a particular disease. Sensitivity and specificity as well as positive and negative predictive value (PPV and NPV) were calculated for all described features using data on their frequency for all analyzed diseases in this review.

\section{Results}

Sensitivity, specificity, PPV, and NPV for all described features are shown in Table 1. All results and data on equipment used in the cited studies are summarized in the online supplementary table (for all online suppl. material, see www.karger.com/doi/10.1159/000517516).

\section{Scalp Psoriasis}

Trichoscopy in scalp psoriasis was evaluated in a total of 12 studies - 8 original studies and 4 case reports - including a total of 218 patients and additionally 48 lesions (number of patients not known) [4, 10-20]. 
Table 1. Sensitivity, specificity, PPV, and NPV of the analyzed trichoscopy features of common inflammatory scalp diseases

\begin{tabular}{|c|c|c|c|c|}
\hline & Sensitivity, \% & Specificity, \% & PPV, \% & NPV, \% \\
\hline \multicolumn{5}{|l|}{ Psoriasis } \\
\hline Diffuse scaling & 12.4 & 100 & 100 & 83.8 \\
\hline Simple red loops & 11.0 & 99.1 & 72.7 & 83.5 \\
\hline Dots and globules & 36.7 & 96.1 & 67.2 & 87.3 \\
\hline Glomerular vessels & 41.3 & 92.9 & 56.3 & 87.8 \\
\hline Twisted red loops & 57.8 & 87.7 & 50.8 & 90.4 \\
\hline White scaling & 50.0 & 82.6 & 38.8 & 88.3 \\
\hline Perifollicular scaling & 50.0 & 53.6 & 19.2 & 83.0 \\
\hline \multicolumn{5}{|l|}{ Seborrheic dermatitis } \\
\hline Structureless red areas & 54.5 & 97.6 & 90.9 & 83.2 \\
\hline Atypical red vessels & 26.0 & 96.9 & 78.5 & 75.2 \\
\hline Yellow dots & 13.2 & 96.2 & 60.0 & 71.9 \\
\hline Arborizing red lines & 49.6 & 90.6 & 69.6 & 80.6 \\
\hline Glomerular vessels & 18.6 & 89.1 & 42.5 & 71.7 \\
\hline White scaling & 43.8 & 85.7 & 56.9 & 77.9 \\
\hline Twisted red loops & 32.9 & 84.8 & 48.4 & 74.5 \\
\hline Perifollicular scaling & 46.0 & 52.5 & 29.5 & 69.2 \\
\hline \multicolumn{5}{|l|}{ Contact dermatitis } \\
\hline Twisted red loops & 20.0 & 79.5 & 0.8 & 99.2 \\
\hline Arborizing red lines & 10.0 & 78.4 & 0.4 & 99.1 \\
\hline \multicolumn{5}{|l|}{ Lichen planopilaris } \\
\hline Milky red areas & 52.2 & 100 & 100 & 83.4 \\
\hline White fibrotic patches & 45.2 & 100 & 100 & 81.4 \\
\hline Perifollicular erythema & 34.0 & 100 & 100 & 78.4 \\
\hline Pigmented halo in targetoid pattern & 32.3 & 100 & 100 & 78.0 \\
\hline Loss of vellus hair & 21.6 & 100 & 100 & 75.4 \\
\hline Perifollicular vessels & 19.4 & 100 & 100 & 74.8 \\
\hline Black dots & 32.0 & 99.8 & 98.3 & 77.9 \\
\hline Pigmented network & 38.2 & 99.4 & 96.5 & 79.4 \\
\hline Tubular casts & 15.2 & 97.0 & 67.5 & 73.3 \\
\hline Loss of follicular units & 83.1 & 96.2 & 90.2 & 93.2 \\
\hline White dots & 20.5 & 92.8 & 54.5 & 73.7 \\
\hline Perifollicular scaling & 63.8 & 59.9 & 39.9 & 79.8 \\
\hline \multicolumn{5}{|l|}{ Discoid lupus erythematosus } \\
\hline Follicular plugs & 44.6 & 100 & 100 & 92.4 \\
\hline Erythema encircling follicles & 29.3 & 100 & 100 & 90.5 \\
\hline Perifollicular whitish halo & 13.4 & 100 & 100 & 88.6 \\
\hline White patches & 19.7 & 99.7 & 91.2 & 89.3 \\
\hline Honeycomb pigmentation & 15.3 & 96.6 & 40.0 & 88.4 \\
\hline Yellow dots & 14.6 & 94.6 & 28.8 & 88.1 \\
\hline White dots & 27.4 & 91.3 & 32.1 & 89.4 \\
\hline Arborizing red lines & 41.4 & 81.5 & 25.0 & 90.3 \\
\hline Loss of follicular units & 18.5 & 71.6 & 8.8 & 85.5 \\
\hline Perifollicular scaling & 40.8 & 52.0 & 11.2 & 85.5 \\
\hline \multicolumn{5}{|l|}{ Pemphigus foliaceus } \\
\hline Scaling - white polygonal structures & 21.4 & 100 & 100 & 98.2 \\
\hline Fried egg sign & 14.3 & 99.2 & 28.6 & 98.0 \\
\hline Yellow hemorrhagic crusts & 64.3 & 97.9 & 41.9 & 99.1 \\
\hline Serpentine vessels & 10.7 & 97.7 & 10.0 & 97.9 \\
\hline Yellow scaling & 42.9 & 97.6 & 29.3 & 98.6 \\
\hline Tubular casts & 32.1 & 94.0 & 11.3 & 98.3 \\
\hline Hemorrhages & 75.0 & 96.0 & 30.9 & 99.4 \\
\hline White perifollicular scaling & 35.7 & 77.1 & 3.6 & 98.1 \\
\hline
\end{tabular}


Table 1 (continued)

\begin{tabular}{|c|c|c|c|c|}
\hline & Sensitivity, \% & Specificity, \% & PPV, \% & NPV, \% \\
\hline \multicolumn{5}{|l|}{ Pemphigus vulgaris } \\
\hline Red dots with whitish halo & 18.9 & 100 & 100 & 97.5 \\
\hline Lace-like vessels & 13.5 & 100 & 100 & 97.3 \\
\hline Fried egg sign & 27.0 & 99.7 & 71.4 & 97.7 \\
\hline Serpentine & 18.9 & 99.7 & 70.0 & 97.5 \\
\hline Yellow scale & 24.3 & 97.3 & 22.0 & 97.6 \\
\hline Hemorrhages & 78.4 & 96.7 & 42.6 & 99.3 \\
\hline Dots and globules & 35.1 & 91.0 & 10.9 & 97.8 \\
\hline \multicolumn{5}{|l|}{ Syphilis } \\
\hline Reduced number of terminal hair shafts & 50.0 & 100 & 100 & 99.6 \\
\hline Broken hairs & 30.0 & 100 & 100 & 99.4 \\
\hline Hemorrhages & 10.0 & 94.4 & 1.5 & 99.2 \\
\hline Yellow dots & 30.0 & 93.6 & 3.8 & 99.4 \\
\hline Pigmented network & 10.0 & 88.3 & 0.7 & 99.2 \\
\hline White scaling & 10.0 & 76.6 & 0.4 & 99.0 \\
\hline Loss of follicular units & 30.0 & 72.9 & 0.9 & 99.2 \\
\hline Perifollicular scaling & 10.0 & 52.6 & 0.2 & 98.6 \\
\hline \multicolumn{5}{|l|}{ Dermatomyositis } \\
\hline Lake-like vascular structures & 14.3 & 100 & 100 & 98 \\
\hline Serpentine vessels & 71.4 & 99.2 & 66.7 & 99.3 \\
\hline Interfollicular scaling & 50.0 & 98.6 & 45.2 & 98.8 \\
\hline Tubular casts & 57.1 & 94.6 & 20.0 & 98.9 \\
\hline
\end{tabular}

Vessels. The most common vessel type observed in the interfollicular region were twisted red loops (126/218 [57.8\%]) [4, 10, 12-15], glomerular vessels $(90 / 218$ [41.3\%]) [10, 12, 14-16], and red dots and globules (80/218 [36.7\%] patients and 46/48 [94\%] lesions) [1018] (Fig. 2a, b). The diameter of homogeneously distributed tortuous and dilated capillaries (bushy pattern) described by Rosina et al. [16] equaled $73 \pm 17 \mu \mathrm{m}$ and in the study by our group $94 \pm 22 \mu \mathrm{m}$ and $112 \pm 33 \mu \mathrm{m}$ for glomerular vessels and twisted loops, respectively [15].

Scaling. White, perifollicular scaling (Fig. 3a) was observed in $109 / 218(50 \%)$ patients $[14,15,19,20]$, but in $48 / 48$ (100\%) lesions reported by Lallas et al. [18], yellow scaling was rarely reported $[15,18]$. The distribution of the scaling was described as diffuse or patchy $[15,18]$.

Other. The most common other dermoscopic features included punctate hemorrhage [14, 15] (Fig. 3b), blotchy erythema [17], and structureless red areas [10].

\section{Seborrheic Dermatitis}

A total of 9 original studies including 365 patients described trichoscopic features of seborrheic dermatitis of the scalp $[4,10,12,14,16,17,21-23]$.

Trichoscopy in Inflammatory Scalp Diseases
Vessels. The most common vascular pattern present in seborrheic dermatitis lesions on the scalp were arborizing red lines (181/365 [49.6\%]) [4, 10, 12, 14, 21-23], twisted red loops $(120 / 365$ [32.9\%]) [4, 10, 12, 14, 2123 ], atypical vessels $(95 / 365$ [26\%], the morphology not precisely described by authors) $[10,12,14]$, and glomerular vessels $(68 / 365$ [18.6\%]) [10, 12, 21-23] (Fig. 2c, d).

Scaling. Perifollicular scaling was described in 168/365 (46\%) patients, white color dominating over yellow/oily scaling [12, 17, 21, 22] (Fig. 3c).

\section{Contact Dermatitis}

One original study and 2 case reports described the trichoscopic features of contact dermatitis of the scalp in a total of 10 patients [24-26]. Twisted red loops [26] and arborizing vessels [25] were reported (Fig. 2e, f). Scaling was also present. However, its color and location was not specified [26] (Fig. 3d).

\section{Lichen Planopilaris}

A total of 22 studies ( 15 original studies, 7 case reports) reported on trichoscopic features of lichen planopilaris. 

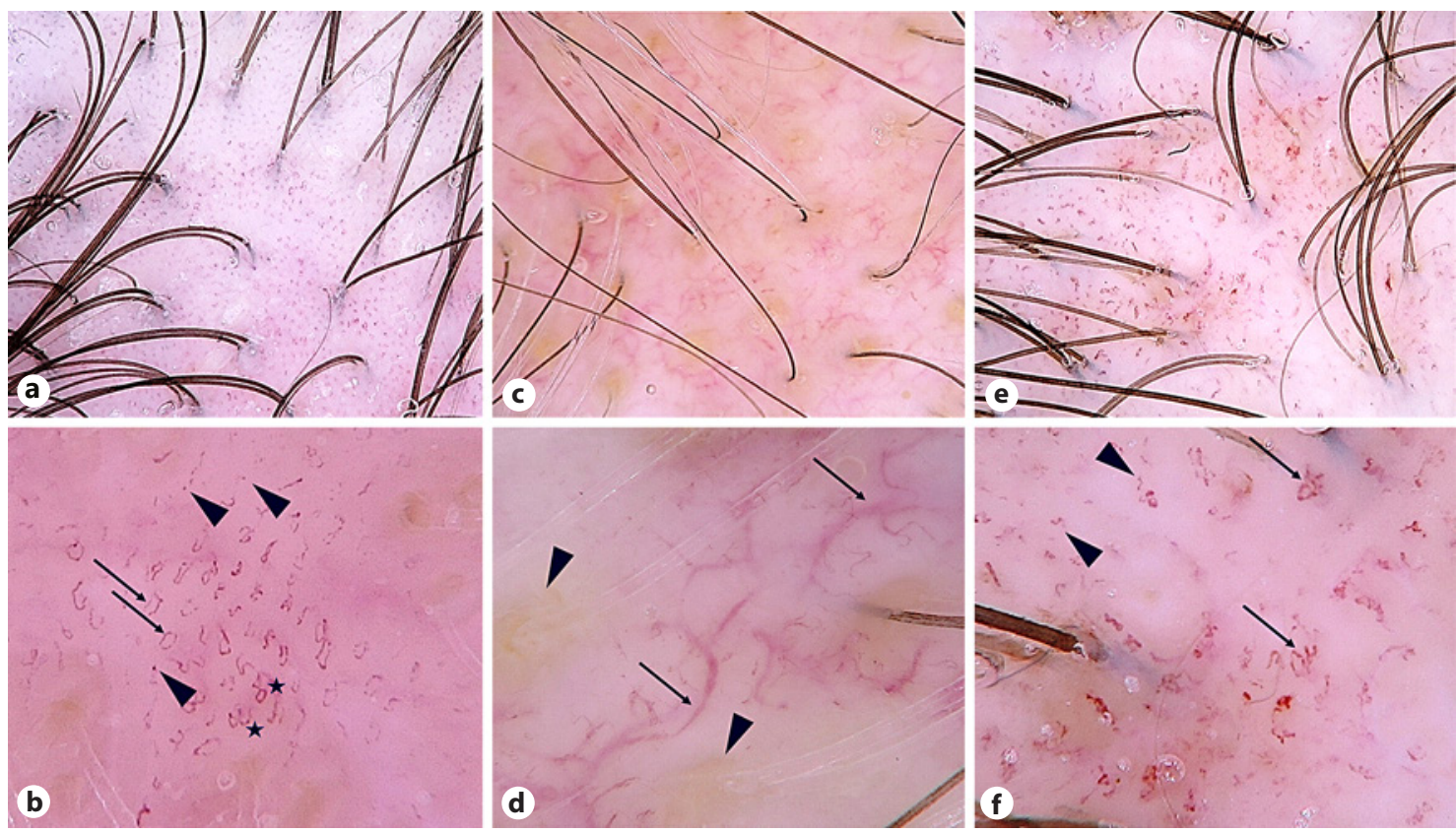

b

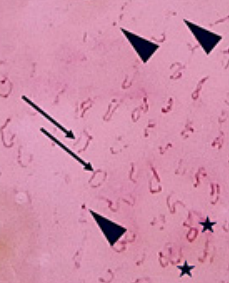

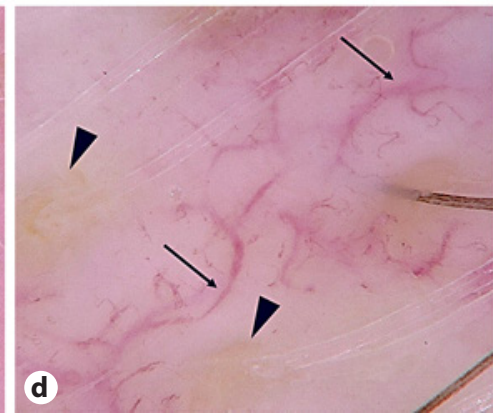

d

Fig. 2. Trichoscopy with immersion. Fotofinder Medicam 1000, Bad Birnbach, Germany. a Psoriasis, $\times 20$. b Psoriasis, $\times 70$; regularly distributed simple red loops (arrows), twisted red loops (stars), and globules (arrowheads). c Seborrheic dermatitis, $\times 20$. d Seborrheic dermatitis, $\times 70$; arborizing red lines (arrows) and yellow dots (arrowheads). e Contact dermatitis, $\times 20$. f Contact dermatitis, $\times 70$; irregularly distributed twisted red loops (arrows) and comma vessels (arrowheads).
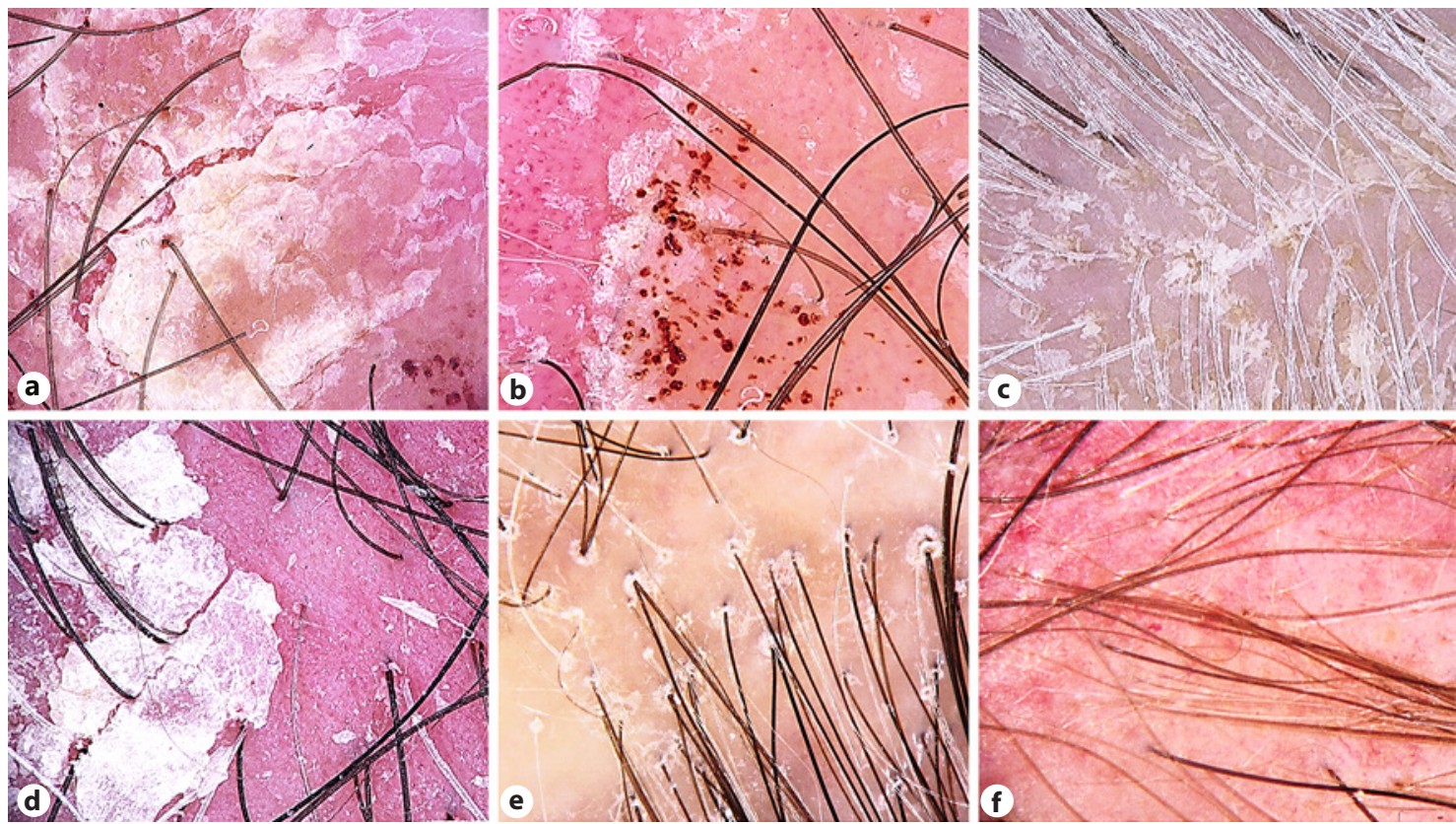

Fig. 3. Trichoscopy, $\times 20$. Fotofinder Medicam 1000, Bad Birnbach, Germany. a Psoriasis - thick layers of whitishyellowish scale. b Psoriasis - hemorrhagic dots in white scale. c Seborrheic dermatitis - regularly distributed whitish-yellowish scale. d Contact dermatitis - thin white scale, patchily distributed. e Lichen planopilaris - silver-white perifollicular scaling. $\mathbf{f}$ Discoid lupus erythematosus - scattered red-brown discoloration of the skin. 


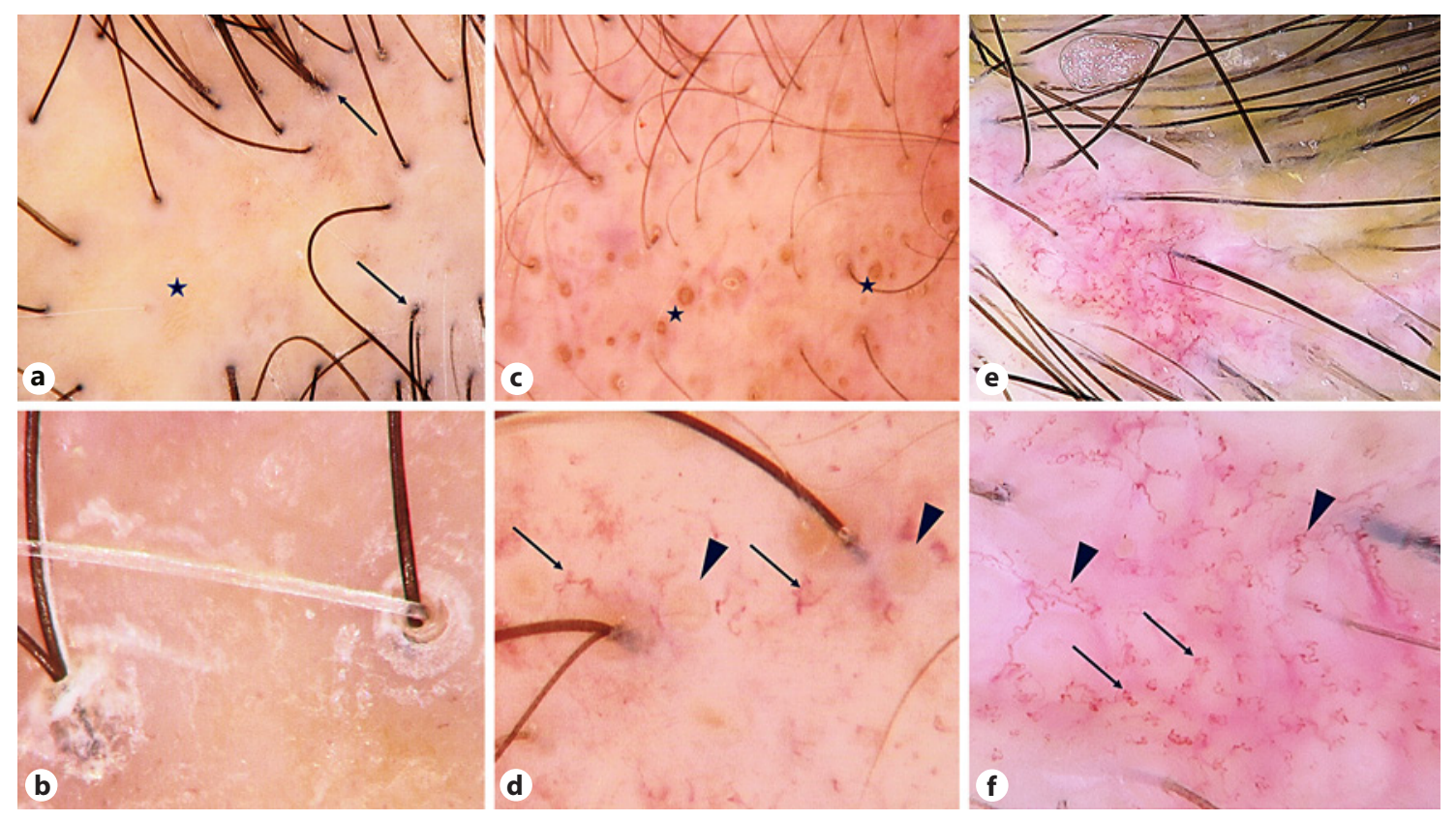

Fig. 4. Trichoscopy. Fotofinder Medicam 1000, Bad Birnbach, Germany. a Lichen planopilaris, $\times 20$ with immersion; structureless area (star) and pigmented halo (arrows). b Lichen planopilaris, $\times 70$; perifollicular scaling with scales entangling hair shafts. c Discoid lupus erythematosus, $\times 20$ with immersion; keratotic plugs (stars). d Discoid lupus erythematosus, $\times 70$ with immersion; arborizing red lines (arrows) and yellow dots (arrowheads). e Pemphigus foliaceus, $\times 20$ with immersion; yellow scale and prominent vascular pattern. $\mathbf{f}$ Pemphigus foliaceus, $\times 70$ with immersion; helical vessels (arrows) and linear serpentine vessels (arrowheads).

The analyzed group consisted of 356 patients $[4,17,27-$ 46].

Vessels. The morphology of vessels was reported in $114 / 356(32 \%)$ patients, most commonly as perifollicular vessels $(69 / 356$ [19.4\%]) [4, 27, 29-33]. Arboriform vessels were reported at the late stage of the disease [45].

Scaling. Perifollicular hyperkeratosis was described in $227 / 356(63.8 \%)$ patients [27, 29, 31, 34-37]. The presence of tubular casts was observed in 54/356 (15.2\%) patients $[17,28,32-34,38-40]$. Peripilar casts were also observed in a case report of late-stage lesions [41] (Fig. 3e, $4 a, b)$.

Other. Fifteen out of 22 studies reported loss of hair follicle units in a total of 296/356 (83.1\%) patients [27, 29-42]. Milky red areas were described in 186/356 (52.2\%) [31-33, 40], white fibrotic patches in 161/356 (45.2\%) [31, $33,36,41,42]$, and perifollicular erythema in 121/356 (34\%) patients [29-31, 33, 35, 42]. Pigmented network, mostly scattered, was another frequent trichoscopic feature observed in 136/356 (38.2\%) [29, 31-36] patients, followed by pigmented halo in targetoid pattern in $115 / 356(32.3 \%)[17,27,28,31-33,43,44]$, black dots in
$114 / 356(32 \%)[17,27,28,31-33,43,44]$, white dots in $73 / 356(20.5 \%)[4,17,27,28,32-44]$, and loss of vellus hair in $77 / 356(21.6 \%)$ patients [31, 32, 37].

\section{Discoid Lupus Erythematosus}

Twelve original studies and 6 case reports, including a total of 157 patients, reported on trichoscopy in discoid lupus erythematosus [4, 17, 28, 29, 33, 36, 44, 47-57].

Vessels. Arborizing red lines were observed in 65/157 (41.4\%) patients [4, 28, 33, 36, 47-50, 53].

Scaling. Follicular hyperkeratosis was reported in $64 / 157(40.8 \%)$ patients [17, 29, 33, 36, 48, 51, 52]. Focal scaling was reported in $2 / 2(100 \%)$ patients by Cervantes et al. [50] and interfollicular scaling in 10/10 (100\%) by Thakur et al. [44]. In a case report, Ankad et al. [28] described the presence of white scaling, whereas Nikam and Mehta [17] observed the presence of flakes of scaling in $3 / 5(60 \%)$ patients in polarized trichoscopy.

Other. Follicular plugs were reported in 70/157 (44.6\%) patients [36, 48-52] (Fig. 4c, d). Loss of follicular ostia was observed in 29/157 (18.5\%) patients [17, 29, 33, 36, $51,53,54]$. Red dots were present in $46 / 157$ (29.3\%) pa- 
tients $[28,52,55]$, whereas white dots were visualized in $43 / 157(27.4 \%)$ patients [17, 36, 52, 56]. Brown discoloration, structureless brown areas (Fig. 3f), perifollicular pigmentation, perifollicular erythema, white rosettes, bluish-white veil-like structures, and large yellow dots with radial, thin arborizing vessels ("red spider in yellow dot") were described [17, 28, 31, 33, 36, 48, 50, 52, 57].

\section{Pemphigus Foliaceus}

Two studies [58,59] and 1 case report [60] reported on trichoscopy in pemphigus foliaceus. Twenty-eight patients were included into the analysis.

Vessels. The reported types of vessels included linear serpentine vessels, dotted vessels, and arborizing vessels. Linear helical vessels and glomerular vessels occurred in single patients and correlated with high Pemphigus Disease Area Index for the scalp and a severe disease course [59] (Fig. 4e, f).

Scaling. Yellow diffuse scaling was observed in $12 / 28$ $(42.9 \%)[58,59]$, white diffuse scaling in $10 / 28(35.7 \%)$ $[58,59]$, and tubular perifollicular scaling in 9/28 (32.1\%) patients $[58,59]$. An additional type of scaling reported in pemphigus foliaceus were white polygonal structures occurring in 6/28 (1.4\%) patients [59].

Other. Extravasations were observed in both studies in $21 / 28(75 \%)$ patients $[58,59]$. Yellow hemorrhagic crusts were observed in 18/28 (64.3\%) patients [58, 59]. Yellow dots with a whitish halo ("fried egg sign") were observed [58-60].

\section{Pemphigus Vulgaris}

Two original studies $[58,59]$ and 2 case reports $[61,62]$ including a total of 37 patients reported on the trichoscopic picture of pemphigus vulgaris.

Vessels. Dotted vessels were the most common vascular feature, described in 13/37 (35.1\%) [58] patients, followed by red dots with whitish halo $[58,59]$, linear-serpentine, lace-like, glomerular, and arborizing vessels [59]. Linear helical and glomerular vessels correlated with high Pemphigus Disease Area Index for the scalp alike in pemphigus foliaceus [59].

Scaling. Yellow diffuse scaling was observed in $9 / 37$ (24.3\%) patients [58].

Other. Extravasations (29/37 [78.4\%]) [58, 59], hemorrhagic crusts $(25 / 37$ [67.6\%]) [58,59,61], and yellow dots with whitish halo (10/37 [27\%]) [58] were observed.

\section{Syphilis}

Trichoscopy of syphilis was described in 1 study [63] and 3 case reports $[64,65]$ including a total of 10 patients.
Dilated capillary vessels were described in one patient [63]. Thin, whitish scaling and perifollicular hyperkeratosis was observed focally in lesions of patient described by Tognetti et al. [65]. Other features were related to abnormalities in hair shaft density or structures and were rather the effect of syphilitic alopecia than inflammatory lesions.

\section{Dermatomyositis}

Our literature search revealed only 1 study including 28 patients [66].

Vessels. Enlarged tortuous capillaries and vascular lake-like structures were observed in 20/28 (71.4\%) and 4/28 (14.3\%) patients, respectively [66]. Bushy vessels were observed in $<50 \%$ of patients [66].

Scaling. Peripilar casts were visualized in 16/28 (57.1\%) and interfollicular scaling in 14/28 (50\%) patients [66].

Other. Other trichoscopy features of dermatomyositis included hair tufts as well as interfollicular and perifollicular pigmentation [66].

\section{Discussion}

Inflammatory scalp dermatoses of different etiology may share clinical similarities. Therefore, trichoscopy as a quick, noninvasive, and in-office diagnostic method may be of significant value in clinical practice.

Differentiation between psoriasis and seborrheic dermatitis of the scalp is the most common clinical dilemma. According to Sticherling [67], white color of the scale on clinical examination indicates psoriasis, whereas yellow scale indicates seborrheic dermatitis [10]. However, according to our literature review, the frequency of white scale is comparable in both dermatoses $(50.0 \%$ and $43.8 \%$ of patients, respectively, $p=0.15$ ). According to Kim et al. [10], the differentiation between psoriasis and seborrheic dermatitis should be performed on the basis of vascular features. This systematic review confirms this observation. The trichoscopy features with the highest specificity for psoriasis are simple red loops and dots and globules, while seborrheic dermatitis may be characterized by comma vessels and arborizing red lines.

The diagnosis of discoid lupus erythematosus and lichen planopilaris also may be problematic in clinical practice [28]. In both diseases crystalline structures marking areas of fibrosis are visible and a "blink sign" was observed [68]. According to Shim et al. [29], the main criterion enabling distinguishing discoid lupus erythematosus from lichen planopilaris is the presence of keratin plugs. Our data indicate that keratin plugs are specific for discoid lu- 
pus erythematosus. The trichoscopic features with the highest specificity for lichen planopilaris were perifollicular vessels, perifollicular erythema, and loss of vellus hairs.

Erythematous lesions on the scalp may also be caused by allergic diseases. Data on the use of trichoscopy in diagnosing contact dermatitis of the scalp are scarce. There are no reports on trichoscopic features of contact dermatitis without concomitant alopecia, which limits the evaluation of the usability of trichoscopy in this indication.

The use of trichoscopy is reported to be efficient also in a group of bullous diseases. The presence of serocrust in coexistence of tubular perifollicular scaling, extravasations, and yellow hemorrhagic crusts on the scalp may indicate pemphigus foliaceus, while extravasations, hemorrhagic crust, and "fried egg sign" may indicate pemphigus vulgaris [58,59]. Yellow hemorrhagic crusts observed in inflammatory diseases analyzed in this review present $100 \%$ specificity for the diagnosis of pemphigus (both vulgaris and foliaceus). However, in the literature yellow hemorrhagic crusts were also reported in diseases associated with pus secretion not included in this review, such as folliculitis decalvans or dissecting cellulitis [57].

\section{Conclusion}

This systematic review indicates that trichoscopy may serve as a useful accessory tool in the differential diagnosis of inflammatory scalp diseases. We identified trichoscopic features of the highest specificity for psoriasis (diffuse and patchy scaling, simple red loops), seborrheic dermatitis (comma vessels, perifollicular pigmentation), contact dermatitis (twisted red loops), lichen planopilaris (milky red areas, fibrotic patches), discoid lupus erythematosus (follicular plugs, erythema encircling follicles), pemphigus foliaceus (scaling - white polygonal struc- tures, serpentine vessels), pemphigus vulgaris (red dots with whitish halo, lace-like vessels), and dermatomyositis (lake-like vascular structures).

\section{Key Message}

Trichoscopy of inflammatory scalp diseases can be used with high accuracy in clinical practice.

\section{Statement of Ethics}

Ethics approval was not required because this review contains only published literature.

\section{Conflict of Interest Statement}

The authors have no conflict of interest to declare.

\section{Funding Sources}

The article has no funding source.

\section{Author Contributions}

J. Golińska made substantial contributions to the conception and design of the study, the acquisition of data, the analysis and interpretation of data, prepared the draft of the article, and gave final approval of the version to be submitted. M. Sar-Pomian made contributions to the conception and design of the study, the analysis and interpretation of data, participated in drafting the article and revising it critically for important intellectual content, and gave final approval of the version to be submitted. L. Rudnicka made contributions to the conception of the study, the analysis and interpretation of data, participated in drafting the article and revising it critically for important intellectual content, and gave final approval of the version to be submitted.

\section{References}

1 Rudnicka L, Olszewska M, Rakowska A, Slowinska M. Trichoscopy update 2011. J Dermatol Case Rep. 2011;5(4):82-8.

2 Mubki T, Rudnicka L, Olszewska M, Shapiro J. Evaluation and diagnosis of the hair loss patient: part II. Trichoscopic and laboratory evaluations. J Am Acad Dermatol. 2014; 71(3):431.e1-11.

3 Lacarrubba F, Dall'Oglio F, Nasca MR, Micali G. Videodermatoscopy enhances diagnostic capability in some forms of hair loss. Am J Clin Dermatol. 2004;5(3):205-8.
4 Ross EK, Vincenzi C, Tosti A. Videodermoscopy in the evaluation of hair and scalp disorders. J Am Acad Dermatol. 2006;55(5):799-806.

5 Rossi A, Fortuna MC, Pranteda G, Garelli V, Di Nunno D, Mari E, et al. Clinical, histologi$\mathrm{cal}$ and trichoscopic correlations in scalp disorders. Dermatology. 2015;231(3):201-8.

6 Seité S, Paries J, Reygagne P, Hamidou Z, Jouanique C, Perez-Pala G, et al. A lipohydroxyacid-containing shampoo improves scalp condition and quality of life in patients with seborrheic dermatitis and light-to-moderate scalp psoriasis. J Cosmet Dermatol. 2009;8(2):108-13.
7 Rudnicka L, Olszewska M, Rakowska A, Kowalska-Oledzka E, Slowinska M. Trichoscopy: a new method for diagnosing hair loss. J Drugs Dermatol. 2008;7(7):651-4.

8 Lacarrubba F, Micali G, Tosti A. Scalp dermoscopy or trichoscopy. Curr Probl Dermatol. 2015;47:21-32.

9 Waśkiel-Burnat A, Rakowska A, Sikora M, Ciechanowicz P, Olszewska M, Rudnicka L. Trichoscopy of tinea capitis: a systematic review. Dermatol Ther (Heidelb). 2020;10(1): 43-52. 
10 Kim GW, Jung HJ, Ko HC, Kim MB, Lee WJ, Lee SJ, et al. Dermoscopy can be useful in differentiating scalp psoriasis from seborrhoeic dermatitis. Br J Dermatol. 2011;164(3):652-6.

11 Campione E, Diluvio L, Terrinoni A, Orlandi A, Latino MP, Torti C, et al. Severe erythrodermic psoriasis in child twins: from clinicalpathological diagnosis to treatment of choice through genetic analyses: two case reports. BMC Res Notes. 2014;7(1):929.

12 Kibar M, Aktan Ş, Bilgin M. Dermoscopic findings in scalp psoriasis and seborrheic dermatitis; two new signs; signet ring vessel and hidden hair. Indian J Dermatol. 2015;60(1): 41-5.

13 Almeida MC, Romiti R, Doche I, Valente NY, Donati A. Psoriatic scarring alopecia. An Bras Dermatol. 2013;88(6 Suppl 1):29-31.

14 Xu C, Chen D, Liu J, Liu Y, Sun Q. Roles of dermoscopy in the diagnosis and differential diagnosis of scalp psoriasis and seborrheic dermatitis. Zhonghua Yi Xue Za Zhi. 2014; 94(44):3467-70. Chinese.

15 Golińska J, Sar -Pomian M, Rudnicka L. Dermoscopy of plaque psoriasis differs with plaque location, its duration, and patient's sex. Skin Res Technol. 2021 Mar;27(2):21726.

16 Rosina P, Zamperetti MR, Giovannini A, Girolomoni G. Videocapillaroscopy in the differential diagnosis between psoriasis and seborrheic dermatitis of the scalp. Dermatology. 2007;214(1):21-4.

17 Nikam VV, Mehta HH. A nonrandomized study of trichoscopy patterns using nonpolarized (contact) and polarized (noncontact) dermatoscopy in hair and shaft disorders. Int J Trichology. 2014;6(2):54-62.

18 Lallas A, Apalla Z, Argenziano G, Sotiriou E, Di Lernia V, Moscarella E, et al. Dermoscopic pattern of psoriatic lesions on specific body sites. Dermatology. 2014;228(3):250-4.

19 Currado D, Margiotta D, Conforti C, Coppola R, Panasiti V, Afeltra A, et al. New onset of psoriasis induced by secukinumab in a patient with ankylosing spondylitis: a case report. Scand J Rheumatol. 2020;49(1):75-6.

20 Özkur E, Altunay İK, Leblebici C, Topkarc1 Z, Erdem Y. Adalimumab-induced scalp psoriasis with severe alopecia. Dermatol Ther. 2019; 32(5):e13033.

21 Dall'Oglio F, Lacarrubba F, Verzì AE, Micali G. Noncorticosteroid combination shampoo versus $1 \%$ ketoconazole shampoo for the management of mild-to-moderate seborrheic dermatitis of the scalp: results from a randomized, investigator-single-blind trial using clinical and trichoscopic evaluation. Skin Appendage Disord. 2015;1(3):126-30.

22 Widaty S, Pusponegoro EH, Rahmayunita G, Astriningrum R, Akhmad AM, Oktarina C, et al. Applicability of trichoscopy in scalp seborrheic dermatitis. Int J Trichology. 2019;11(2): $43-8$.
23 Ruiz-Arriaga LF, Arenas R, Vega-Sánchez DC, Asz-Sigall D, Martínez-Velazco MA. Seborrheic dermatitis: three novel trichoscopic signs and its correlation to Malassezia sp. colonization. Skin Appendage Disord. 2019;5(5):288-92.

24 Tosti A, Donati A, Vincenzi C, Fabbrocini G. Videodermoscopy does not enhance diagnosis of scalp contact dermatitis due to topical minoxidil. Int J Trichology. 2009;1(2):134-7.

25 Hughes OB, Maderal AD, Tosti A. An unusual case of contact dermatitis. Skin Appendage Disord. 2017;3(3):163-5.

26 La Placa M, Balestri R, Bardazzi F, Vincenzi C. Scalp psoriasiform contact dermatitis with acute telogen effluvium due to topical minoxidil treatment. Skin Appendage Disord. 2016;1(3):141-3.

27 Soares VC, Mulinari-Brenner F, Souza TE. Lichen planopilaris epidemiology: a retrospective study of 80 cases. An Bras Dermatol. 2015;90(5):666-70.

28 Ankad BS, Beergouder SL, Moodalgiri VM. Lichen planopilaris versus discoid lupus erythematosus: a trichoscopic perspective. Int J Trichology. 2013;5(4):204-7.

29 Shim WH, Jwa SW, Song M, Kim HS, Ko HC, Kim BS, et al. Dermoscopic approach to a small round to oval hairless patch on the scalp. Ann Dermatol. 2014;26(2):214-20.

30 Friedman P, Sabban EC, Marcucci C, Peralta $\mathrm{R}$, Cabo H. Dermoscopic findings in different clinical variants of lichen planus. Is dermoscopy useful? Dermatol Pract Concept. 2015; 5(4):51-5.

31 Lajevardi V, Mahmoudi H, Moghanlou S, Ansari M, Teimourpour A, Daneshpazhooh M. Assessing the correlation between trichoscopic features in lichen planopilaris and lichen planopilaris activity index. Australas J Dermatol. 2019;60(3):214-8.

32 Eftekhari H, Azimi SZ, Rafiei R, Darjani A, Alizadeh N, Rafiei E, et al. Dermoscopic features of lichen planopilaris in Northern Iran: a prospective observational study. Int J Dermatol. 2019;58(12):1406-14.

33 Thakur BK, Verma S, Raphael V. Clinical, trichoscopic, and histopathological features of primary cicatricial alopecias: a retrospective observational study at a tertiary care centre of North East India. Int J Trichology. 2015;7(3):107-12.

34 Morais KL, Martins CF, Anzai A, Valente NYS, Romiti R. Lichen planopilaris with pustules: a diagnostic challenge. Skin Appendage Disord. 2018;4(2):61-6.

35 Góes HFO, Dias MFRG, Salles SAN, Lima CDS, Vieira MDS, Pantaleão L. Lichen planopilaris developed during childhood. An Bras Dermatol. 2017;92(4):543-5.

36 Zeeshan M, Chaudhary RKP, Roy PK, Jha AK. Dermoscopy in selected disorders of scarring alopecia. J Pak Assoc Dermatol. 2018;28(4): 449-51.

37 Karadag Köse Ö, Güleç AT. Evaluation of a handheld dermatoscope in clinical diagnosis of primary cicatricial alopecias. Dermatol Ther (Heidelb). 2019;9(3):525-35.
38 Nirmal B, George R, Kodiatte TA. Invisible lichen planopilaris unmasked by dermatoscopy. Int J Trichology. 2017;9(2):76-8.

39 Randolph MJ, Salhi WA, Tosti A. Lichen planopilaris and low-level light therapy: four case reports and review of the literature about low-level light therapy and lichenoid dermatosis. Dermatol Ther (Heidelb). 2020;10(2): 311-9.

40 Batra P, Sukhdeo K, Shapiro J. Hair loss in lichen planopilaris and frontal fibrosing alopecia: not always irreversible. Skin Appendage Disord. 2020;6(2):125-9.

41 Arshdeep Batrani M, Kubba A, Kubba R. Lichen planopilaris beyond scalp: a case series with dermoscopy-histopathology correlation. Int J Dermatol. 2018 Nov;57(11):e127-31.

42 Starace M, Orlando G, Alessandrini A, Baraldi C, Bruni F, Piraccini BM. Diffuse variants of scalp lichen planopilaris: clinical, trichoscopic, and histopathologic features of $40 \mathrm{pa}-$ tients. J Am Acad Dermatol. 2020;83:1659.

43 Kaliyadan F, Ameer AA. Localized and linear lichen planopilaris over the face and scalp with associated alopecia - clinical and dermoscopy pattern. Dermatol Online J. 2015; 21(9):21.

44 Mathur M, Acharya P, Karki A, Shah J, Kc N Tubular hair casts in trichoscopy of hair and scalp disorders. Int J Trichology. 2019;11(1): 14-9.

45 Rossi A, Iorio A, Scali E, Gerardi M, Priolo L, Misciali C, et al. Frontal fibrosing alopecia and lichen planopilaris: clinical, dermoscopic and histological comparison. Eur J Inflamm. 2013;11(1):311-4.

46 Andziukeviciute AJ, Makstiene J, Valiukeviciene S. Trichoscopy as an additional diagnostic tool for monitoring of lichen planopilaris: A case report. Akt Dermatol. 2016;42: 280-82.

47 Melo DF, De Carvalho N, Ardigò M, Pellacani G, Mota ANCM, Barreto TM, et al. Concordance among in vivo reflectance confocal microscopy, trichoscopy, and histopathology in the evaluation of scalp discoid lupus. Skin Res Technol. 2020;26:675.

48 Jha AK, Sonthalia S, Sarkar R. Dermoscopy of discoid lupus erythematosus. Indian Dermatol Online J. 2016;7(5):458.

49 Almurayshid A, Al Obaid S. Isolated linear discoid lupus erythematosus of scalp following lines of Blaschko. Open Dermatol J. 2019; 13(1):58-60.

50 Cervantes J, Hafeez F, Miteva M. Blue-white veil as novel dermatoscopic feature in discoid lupus erythematosus in 2 African-American patients. Skin Appendage Disord. 2017;3(4): 211-4.

51 Lanuti E, Miteva M, Romanelli P, Tosti A. Trichoscopy and histopathology of follicular keratotic plugs in scalp discoid lupus erythematosus. Int J Trichology. 2012;4(1):36.

52 Al-Refu K. The role of dermoscopy in assessment of the activity and scarring response in discoid lupus erythematosus. Open Dermatol J. 2018;12(1):99-111. 
53 Nascimento LLD, Enokihara MMSES, Vasconcellos MRA. Coexistence of chronic cutaneous lupus erythematosus and frontal fibrosing alopecia. An Bras Dermatol. 2018; 93(2):274-6.

54 Souissi A, Ben Tanfous A, Azzouz H, Karray M, Zghal M, El Euch D, et al. When trichoscopy enlightens clinics. Int J Dermatol. 2016; 55(11):1278-80.

55 Tosti A, Torres F, Misciali C, Vincenzi C, Starace $\mathrm{M}$, Miteva $\mathrm{M}$, et al. Follicular red dots: a novel dermoscopic pattern observed in scalp discoid lupus erythematosus. Arch Dermatol. 2009;145(12):1406-9.

56 Ankad BS, Shah SD, Adya KA. White rosettes in discoid lupus erythematosus: a new dermoscopic observation. Dermatol Pract Concept. 2017;7(4):9-11.

57 Rakowska A, Slowinska M, Kowalska-Oledzka E, Warszawik O, Czuwara J, Olszewska M, et al. Trichoscopy of cicatricial alopecia. J Drugs Dermatol. 2012;11(6):753-8.
58 Sar-Pomian M, Rudnicka L, Olszewska M. Trichoscopy - a useful tool in the preliminary differential diagnosis of autoimmune bullous diseases. Int J Dermatol. 2017;56(10):9961002.

59 Sar-Pomian M, Kurzeja M, Rudnicka L, Olszewska $M$. The value of trichoscopy in the differential diagnosis of scalp lesions in pemphigus vulgaris and pemphigus foliaceus. An Bras Dermatol. 2014;89(6):1007-12.

60 Ghiasi M, Nasimi M, Ghanadan A, Azizzadeh-Roodpishi S. "Fried egg sign": a trichoscopic feature in scalp pemphigus. J Eur Acad Dermatol Venereol. 2020;34(6):e283-4.

61 Bosseila M, Nabarawy EA, Latif MA, Doss S, ElKalioby M, Saleh MA. Scalp pemphigus vulgaris mimicking folliculitis decalvans: a case report. Dermatol Pract Concept. 2019; 9(3):215-7.

62 Pirmez R. Acantholytic hair casts: a dermoscopic sign of pemphigus vulgaris of the scalp. Int J Trichology. 2012;4(3):172-3.
63 Piraccini BM, Broccoli A, Starace M, Gaspari V, D'Antuono A, Dika E, et al. Hair and scalp manifestations in secondary syphilis: epidemiology, clinical features and trichoscopy. Dermatology. 2015;231(2):171-6.

64 Ye Y, Zhang X, Zhao Y, Gong Y, Yang J, Li H, et al. The clinical and trichoscopic features of syphilitic alopecia. J Dermatol Case Rep. 2014;8(3):78-80.

65 Tognetti L, Cinotti E, Perrot JL, Campoli M, Rubegni P. Syphilitic alopecia: uncommon trichoscopic findings. Dermatol Pract Concept. 2017;7(3):55-9.

66 Jasso-Olivares JC, Tosti A, Miteva M, Domínguez-Cherit J, Díaz-González JM. Clinical and dermoscopic features of the scalp in 31 patients with dermatomyositis. Skin Appendage Disord. 2017;3(3):119-24.

67 Sticherling M. Psoriasis capitis und seborrhoisches Ekzem der Kopfhaut. Hautarzt. 2017;68(6):457-65.

68 Nirmal B, George R. Blink sign in dermatoscopy of cicatricial alopecia. Int J Dermatol. 2019;58(11):e231-2. 